\title{
Radioisotope-guided localization and resection of non-palpable focal lesion of the rib
}

\author{
Francesco Petrella ${ }^{1,2}$, Giorgio Lo Iacono ${ }^{1}$, Monica Casiraghi ${ }^{1}$, Lorenzo Gherzi ${ }^{1}$, Elena Prisciandaro ${ }^{1}$, \\ Cristiano Rampinelli ${ }^{3}$, Marzia Colandrea ${ }^{4}$, Chiara Maria Grana ${ }^{4}$, Lorenzo Spaggiari ${ }^{1,2}$ \\ ${ }^{1}$ Department of Thoracic Surgery, IRCCS European Institute of Oncology, Milan, Italy; ${ }^{2}$ Department of Oncology and Hemato-oncology, \\ University of Milan, Milan, Italy; ${ }^{3}$ Department of Radiology, ${ }^{4}$ Department of Nuclear Medicine, IRCCS European Institute of Oncology, Milan, \\ Italy \\ Correspondence to: Francesco Petrella, MD, PhD. Department of Thoracic Surgery, European Institute of Oncology, Via Ripamonti, 435, Milan, Italy; \\ Department of Oncology and Hemato-oncology, University of Milan, Milan, Italy. Email: francesco.petrella@ieo.it; francesco.petrella@unimi.it.
}

Submitted Jul 15, 2019. Accepted for publication Jul 18, 2019.

doi: $10.21037 /$ jtd.2019.07.87

View this article at: http://dx.doi.org/10.21037/jtd.2019.07.87

\section{Introduction}

Excisional biopsy of non-palpable rib tumors still represents a challenge for thoracic surgeons: in fact primary or metastatic tumors originating from a rib can be difficult to localize topographically at the time of excisional biopsy, thus potentially resulting in inappropriately placed skin incisions, incomplete tumor excision or even in wrong rib or segment resection (1).

Several techniques have been proposed to help in the localization of non-palpable rib lesions for biopsy, including preoperative skin marking, wire-guided biopsies, imaging guided percutaneous biopsies, preoperative methylene blue staining, and scintigraphy with radiopaque markers (2-7). Each of the above mentioned techniques, however, present several limitations and their sensitivity and accuracy are still far from $100 \%$ (8).

Here we report our technique of non-palpable focal rib lesion localization by computed tomography-guided local ${ }^{99 \mathrm{~m}} \mathrm{Tc}$ injection and intraoperative detection by gamma probe [radio-guided occult lesion localization (ROLL)] (9).

\section{Surgical technique}

Once detected a focal non-palpable rib lesion by conventional preoperative exams-computed tomography (CT) and positron emission tomography (PET), the patient is submitted to CT scan in the lateral decubitus planned for surgical excision After identifying the target lesion, an activity of $20-25 \mathrm{MBq}$ of technetium macroaggregated albumin $\left({ }^{99 \mathrm{~m}} \mathrm{Tc}\right.$ MAA) is injected into the lesion under CT scan guidance. Planar scans of the chest area in anterior and lateral projections were obtained $20 \mathrm{~min}$ after radiotracer injection. A cutaneous marker was positioned in correspondence of the focal uptake and a 57Co wire source was used to design body contour. Exact localization of hot spot was checked by a gamma probe. It is of paramount importance that the patient's decubitus will be the same of the surgical procedure and therefore the presence of one member of the surgical team is strongly recommended during this phase. Shortly after the procedure, the patient is then transferred to the operative room where, under general anesthesia and double lumen ventilation, is positioned in the same decubitus.

Thanks to the skin mark, surgical incision is performed on the target lesion. A hand-held gamma probe (as for sentinel lymph node biopsy) is then used to guide intraoperative identification of the involved rib that is then reached and isolated, in this case extrapleurally without opening the chest, and then resected. In case of small resection, there is no need of reconstruction and soft tissue are standardly sutured (Figure 1).

\section{Discussion}

Intraoperative localization of a non-palpable rib lesion presents obstacles that are inherent to the procedure itself: in particular, wire positioning or simple skin marking over the abnormality during preoperative imaging can be 


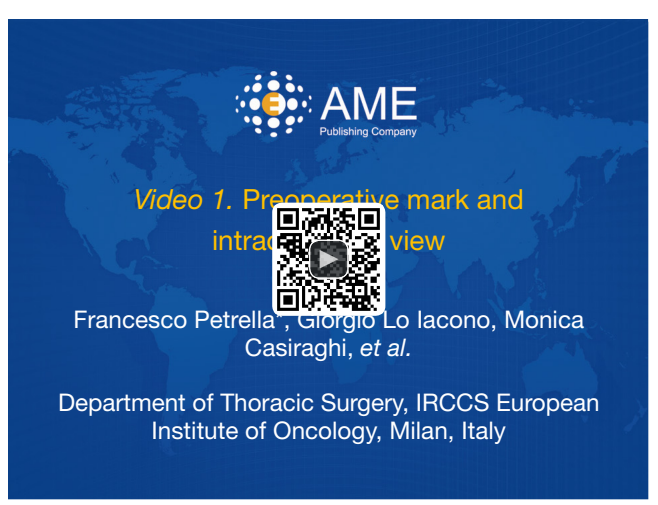

Figure 1 Preoperative mark and intraoperative view (10). Available online: http://www.asvide.com/watch/33067

misleading due to the remarkable shifting of skin and soft tissues in relation to bone that occurs during repositioning for surgical exposure. This may culminate in misleading results, in particular in the chest wall where consistent shifting frequently occurs due to repositioning of the patient and of the arms; moreover, rib counting, wires or methylene blue staining may be inaccurate in obese or very muscular patients $(8,9,11-13)$. Thanks to recent advancements, many focal rib lesions can be preoperatively detected by CT and PET (14); nevertheless, it can be difficult to correctly localize target lesions for its biopsy, in particular in case of non-palpable lesion; moreover, it is of paramount importance an adequate preoperative marking for an optimal patient positioning and to select the most appropriate surgical access.

After pioneering experience with sentinel node biopsy in breast cancer and melanoma, the role of radioisotopes has been widely investigated in the field of thoracic surgerywith particular regard to mediastinal lymph node scattering of tumor cells-with encouraging although not conclusive results (15); on the contrary, the use of local injection of ${ }^{99 m}$ TC-MAA for non-palpable focal rib lesion localization has shown promising results, allowing to overcome the limits of older procedures.

In conclusion, preoperative labelling should always be recommended in case of planned surgical biopsy or radical resection of non-palpable rib lesion and CT guided ${ }^{99 \mathrm{~m}}$ TC-MAA local injection is one of the most effective and reproducible techniques.

\section{Acknowledgments}

None.

\section{Footnote}

Conflicts of Interest: The authors have no conflicts of interest to declare.

Ethical Statement: The authors are accountable for all aspects of the work in ensuring that questions related to the accuracy or integrity of any part of the work are appropriately investigated and resolved. The patient was informed that his clinical data could be used for various clinical studies, and written informed consent was obtained on this basis.

\section{References}

1. McDonald JM, Freeman RK. Thoracoscopic localization of nonpalpable rib tumors for excisional biopsy. Ann Thorac Surg 2000;70:318-9.

2. Froelich JW, McKusick KA, Strauss HW, et al. Localization of bone lesions for open biopsy. Radiology 1983;146:549-50.

3. Hardy DC, Totty, WG, Funk KC. CT-directed rib biopsy. J Comput Assist Tomogr. 1987;11:994-7.

4. Debnam JW, Staple TW. Needle biopsy of bone. Radiol Clin North Am 1975;13:157-64.

5. Ng CS, Salisbury JR, Darby AJ, et al. Radiologically guided bone biopsy: results of 502 biopsies. Cardiovasc Intervent Radiol 1998;21:122-8.

6. Moores DWO, Lines B, Dziuban SW Jr, et al. Nuclear scan-guided rib biopsy. J Thorac Cardiovasc Surg 1990;99:620-1.

7. Little AG, DeMeester TR, Kirchner PT, et al. Guided biopsies of abnormalities on nuclear bone scans. J Thorac Cardiovasc Surg 1983;85:396-403.

8. Fernandes DS, Aye RW, Garnett DJ et al. Targetspecific rib biopsy using the gamma probe. Am J Surg 2000;179:389-90.

9. De Cicco C, Pizzamiglio M, Trifirò G, et al. Radioguided occult lesion localisation (ROLL) and surgical biopsy in breast cancer. Technical aspects Q J Nucl Med 2002;46:145-51.

10. Petrella F, Lo Iacono G, Casiraghi M, et al. Preoperative mark and intraoperative view. Asvide 2020;7:020. Available online: http://www.asvide.com/watch/33067

11. Petrella F, Radice D, Borri A, et al. The impact of preoperative body mass index on respiratory complications after pneumonectomy for non-small-cell lung cancer. Results from a series of 154 consecutive 
standard pneumonectomies. Eur J Cardiothorac Surg 2011;39:738-44.

12. Spaggiari L, Galetta D, Veronesi G, et al. Superior vena cava replacement for lung cancer using a heterologous (bovine) prosthesis: Preliminary results. J Thorac Cardiovasc Surg 2006;131:490-1.

13. Spaggiari L, Tessitore A, Casiraghi M, et al. Survival after extended resection for mediastinal advanced lung cancer: lessons learned on 167 consecutive cases. Ann Thorac Surg

Cite this article as: Petrella F, Lo Iacono G, Casiraghi M, Gherzi L, Prisciandaro E, Rampinelli C, Colandrea M, Grana CM, Spaggiari L. Radioisotope-guided localization and resection of non-palpable focal lesion of the rib. J Thorac Dis 2020;12(1):36-38. doi: 10.21037/jtd.2019.07.87
2013;95:1717-25.

14. Choi HS, Yoo IeR, Park HL, et al. Role of ${ }^{18} \mathrm{~F}-\mathrm{FDG}$ PET/CT in differentiation of a benign lesion and metastasis on the ribs of cancer patients. Clin Imaging 2014;38:109-14.

15. Rzyman W, Hagen OM, Dziadziuszko R, et al. Intraoperative, radio-guided sentinel lymph node mapping in 110 nonsmall cell lung cancer patients. Ann Thorac Surg 2006;82:237-42. 